\title{
Assessing the Effectiveness of Electric Conservation Advertisements in Isfahan Channel Television
}

\author{
Bahram Ranjbarian \\ Department of Management, Faculty of Administrative Science \& Economics \\ University of Isfahan, Iran \\ E-mail: bahram1r@yahoo.com \\ Ali Shaemi \\ Department of Management, Faculty of Administrative Science \& Economics \\ University of Isfahan, Iran \\ E-mail: Alishaemi@yahoo.com \\ Seyyed Yaser Ebrahimian Jolodar \\ Department of Management, Faculty of Administrative Science \& Economics \\ University of Isfahan, Iran \\ E-mail: sy_ebrahimian_j@yahoo.com
}

Received: February 23, 2011

Accepted: March 14, 2011

doi:10.5539/ibr.v4n3p194

\begin{abstract}
Nowadays consumers are bombarded with different ads and the sheer abundance of advertisements causes marketers to be increasingly concerned with advertising effectiveness. Consequently, marketers and advertising companies exploring advertising effectiveness are always looking for more effective and newer communication media and evaluation methods of advertising effectiveness that technological development could provide. This study aims to incorporate AIDA model as hierarchy effect models for measuring the effectiveness of the TV advertisements for electric conservation in Isfahan city. Specifically this study aimed to evaluate the effects of TV advertisement on audience's attention, interest, desire for action and eventually changes made in conservation behavior of audience. The study revealed that the electric conservation TV advertisements were effective. In fact, TV advertisement was successful in taking attention of audience, creating interest and desire for action, and eventually was effective in behavioral change.
\end{abstract}

Keywords: Advertisement effectiveness, TV Advertisement, AIDA model

\section{Introduction}

The implication of marketing concept in non-business area which named social marketing is rapidly growing and had considerable effects on consumption patterns. Social marketing seeks to utilize tools, techniques and concepts derived from commercial marketing to pursue social goals (Andreasen,2006).Today, all organizations are not only looking for more profit and personal interests, but they have a superior goal and it is to influence on individuals' actions and behavior. Social marketing initiatives focus on changing behavior to increase the well-being of individuals and or society. Social marketing seeks to go beyond changing attitudes to changing behavior, and to ensure that new behaviors, once adopted, are maintained (Peattie and Peattie, 2009). It also has strong linkage with entertainment and the proliferation of media has blurred the distinguishing lines between advertisements and entertainment (Moore, 2004; Priya et al., 2009).

Advertising as a marketing tool has a considered important role in changing social behavior. Today, advertising companies invest huge amounts of their earnings in advertising in different media such as television, radio, magazine and etc., that television is one of the prevalent media for this purpose. Rice and Atkin (2001) note that, television is generally assumed to have massive effects on viewers for a variety of reasons. First, a great deal of money is spent on advertising, and big spenders are assumed to know what they are doing. Also, people spend a deplorable percentage of their waking hours in front of television sets, presumably with proportional effects. 
Ramalingam et al.( 2006) note that, TV as an advertising media has three key advantages. First, its influence on consumers' taste and perception is pervasive. Second, it can reach a large audience in a cost-efficient manner. Third, its sound and moving images create a strong impact (Ramalingam et al., 2006).

In most countries, different organization spends annually a big sum of money for marketing and public relations in direct and indirect form. But unfortunately, consideration to assessment of advertising effectiveness is less and only some organizations and industries evaluate the effectiveness of their advertising (Macarthy, 2000).In fact, with a view to the total budget of most small and large business enterprises, we can see that a considerable amount of budget have been allocated for advertising as in comparison with other costs, such as human resource. But, all advertisers and advertising agencies should know that although measuring various effects of advertising is difficult but the results will be very useful for planning, reform and adjustment of organizations advertising activities.

Organization can explicitly determine the effectiveness of their advertising by introduce some questions such as: Whether the advertising program has been able to managed communication and sales goals and realized them or not? Whether we reached the results that we wanted to have or not? Whether our advertising basically has moved towards its target or not? In fact, advertising program must regularly analyze the sales and communication goals and to see whether advertising has been able to basically communicate with the audience or not (Mohammadian, 2006)?

To help evaluate the extent to which advertising dollars are earning the best return on investment, it is important to know how effectively television advertising are able to capture and maintain audience attention and how likely they are to engage the cognitive processing of the consumer to an extent comparable to objectives. However, the cost per view and the effectiveness are still in question (Patsioura, 2009).

In fact, each advertisement can be effective only when its explicit objectives should drive the planning, creation, and execution. Advertisement should work with other forms of marketing communication to reach customers. Thus, advertising companies are always highly interested to evaluate the effectiveness of their advertising in different media, specially in TV. That is the reason why the present study tried to investigate the effectiveness of electric conservation advertisements in Isfahan channel television.

\section{Evaluation Models of Advertisement Effectiveness}

Through the history of advertising research, several different models have been suggested to explain how advertising works in different situations. These models can be categorized as the market response model, intermediate effect model, hierarchy effect model (Vakratsas and Tim, 1999).

\subsection{Market Response Model}

The market response model assumes no intermediate effects in the analysis of the results of advertisements. That is to say that it relates advertising, price, and promotions directly to consumer behaviors not including mediating and moderating factors in the model. Two different levels exist in the market response model: aggregate level (Rao, 1986; Zufryden, 1987) and individual level (Pedrick and Zufryden, 1991). Aggregate level studies focus on the market level data, whereas individual level studies are oriented to the individual brand choice. Generally, the market response model is more suitable for the decision makers within marketing departments in industry (Vakratsas and Tim, 1999).

\subsection{Intermediate Effect Models}

The cognitive information model and pure affect model assume only one type of intermediate effect: cognition or affect. The cognitive information model assumes that consumer preferences do not change by advertisement, and that the consumer decides only rationally. In this model, products are classified as experience, search, and credence goods. Experience goods are the products which require a fair amount of experience before assessing the quality. Search goods are products whose quality can be found out by inspection (Nelson, 1974). For credence goods, the average consumer cannot determine the quality even after using it. It is claimed that advertisements are expected to be more effective for experience and credence goods because they provide information which could not be found just by inspection (Darby and Karni, 1973).

\subsection{Hierarchy of Effects Models in Advertising}

The hierarchy effect model tries to explain consumer behavior by introducing the concept of a hierarchy of effects. These models are suitable tools for editing and evaluating of advertisement goals. These models are also used in promotions planning of products and service.The steps of these models, try to express potential audiences' reaction in a more detailed. In first step a kind of consumer, become aware of a product or an idea and he or she gain more understanding about it. Then, awareness leads to interest, interest lead to preferring and persuasion and finally leads to action or a behavior. Marketers have to design independent programs to have a stronger chance in achieving each 
of these steps. In other words, they assume a certain number of stages, which each of them works as a precondition of the next stage. The traditional hierarchy framework asserts that consumers respond to advertising messages in a very ordered way.

Researchers categorized the functions of advertisement as awareness, knowledge, linking, preference, conviction, and purchase. Each function was mapped to three different behavioral dimensions: cognitive, affective, and connotative component. In other words, awareness and knowledge are related to the cognitive component, linking and preference are associated with the affective component, and finally, conviction and purchase are connected with connotative or motivational component (Lavidge and Steiner, 1961). The recent 'association model (Preston and Thorson, 1984) supports the traditional hierarchy of effects framework, and focuses on a comprehensive advertising process that takes into consideration advertising research techniques(e.g., syndicated data, surveys, experimentation) and concepts consistent with behavioral intentions models.

While there is fundamental agreement regarding the importance of the three stages of the hierarchy among advertising researchers (Barry and Howard, 1990), there has been significant discrepancy regarding the order of the three stages. For example, Krugman (1965) suggested a cognition-conation-affect sequence as an alternative model in low involvement situations. On the other hand, Zajonc and Markus (1982) suggest an affect-conation-cognition sequence, in which preferences do not require a cognitive basis, but instead are mainly affectively based. Ray et al. (1973) suggested another alternative sequence (i.e., conation-affect-cognition), in which consumers' purchasing behavior comes first, attitudes are then formed to reinforce their choice, and selective learning follows to further support purchase decisions. The several alternatives to the original Lavidge and Steiner's model (1961) suggest that advertising researchers have developed different hierarchical models for various consumer decision making situations, but agree on the importance of the three basic tenets (i.e., cognition, affect, and conation) of the hierarchy of effects model.

\section{Research model and Hypotheses}

The main purpose of this study was to assess the effectiveness of TV advertisements regarding electric conservation in Isfahan city. Specifically this study evaluated the influence of advertisement on audiences' attention, interest, desire and eventually changes made in behavior of audience. For this purpose, we used AIDA model as hierarchy effect models. The AIDA model was developed in the 1920s based on the argument that effective personal sales presentations should attract attention, gain interest, create a desire, and precipitate action (Mackey, 2005). It is one of the many models of marketing communications based on a hierarchy of effects because, simplistically, it is assumed that learning about a product will lead to feelings about the product that result in the purchase of the product. It is a learn feel buy model of consumer reactions to communications. The AIDA model is an acronym for:

1. A- Attention (Awareness): attract the attention of the customer. The object here is to get your potential customer to actually stop and take notice of your offering.

2. I- Interest: raise customer interest by demonstrating features, advantages, and benefits. Once you have captured your customer's attention you have to proceed to grow their interest in the product. You need to get in there and show and tell how the product/service you are selling is going to help them.

3. D- Desire: convince customers that they want and desire the product or service and that it will satisfy their needs. A more difficult stage of the process in applying the AIDA model in web based marketing is creating a real desire for the product. One of the most popular applications is using image sliders or content switchers.

4. A- Action: lead customers towards taking action and or purchasing. This step in the process is where you can really use your creativity to get the customer to take action, buying your product/service.

Nowadays some have added another dimension to the model and they formed AIDAS which $\mathrm{S}$ stand for Satisfaction:

5. S- Satisfaction: satisfy the customer so they become a repeat customer and give referrals to a product.

Based on the above mentioned model the following hypotheses are developed:

H1. Electric conservation advertisements in Isfahan channel television have been effective in attracting attentions.

H2. Electric conservation advertisements in Isfahan channel television have been effective in creating interest.

H3. Electric conservation advertisements in Isfahan channel television have been effective in creating desire.

H4. Electric conservation advertisements in Isfahan channel television have been effective in changing consumption behavior. 


\section{Research Methodology}

\subsection{Research Design}

This research can be categorized as descriptive research based on the method of obtaining the considered data. Since these data are made for studying the distribution of statistical population characteristics through sampling of population, this research is a survey done on the basis of cross sectional method.

The data gathering instrument was a self administered questionnaire which consists of two sections. The first part records the respondents' demographic data and the second part designed to test the hypotheses which had been formed basis on AIDA model. This part contains 23 questions in total that questions from 1 to 5 measure the first variable (i.e., attention toward action) according to the first stage of AIDA model. Questions from 6 to 10 measure the second variable (i.e., interest for action) according to the second stage of AIDA model. Questions from 11 to 16 measure the second variable (i.e., desire for action) according to the third stage of AIDA model and eventually questions from 17 to 23 measure the fourth variable (i.e., behavioral change) according to the fourth stage of AIDA model. All the items were measured using five-point Likert scale items with anchor points $1=$ strongly disagree and $5=$ strongly agree To analyze the hypotheses of the study, one-sample $\tau$-test has been used. Also for testing the existence of linear relations between variables, Pearson correlation was used. Finally, to determine the extent of the effects of three variables (i.e., attention toward action, interest and desire for action) on conservation behavior, regression analysis has been used.

\subsection{Statistical Population and Sample}

The statistical population of this research is the citizens of Isfahan city. Since the statistical population was unlimited, therefore the following formula was used to get the size of the sample:

$$
n=\frac{z^{2} \frac{\alpha}{2} \cdot \delta^{2}}{d^{2}}
$$

The variance of answers from the primary sample have obtained.815, and by putting it in the above mentioned formula, the reliability level $(\alpha)$ was 95 percent, and estimate accuracy (E) was 0.1 , the sample size was 255 . But, 10 gathered questionnaire from responders were not complete and useful for analysis. So, we have done our analysis by using 245 complete questionnaire.

For testing the reliability of data gathering instrument, the designed questionnaire distributed among 30 citizen of Isfahan city as a pilot study.. The results of the primary sample show that Cronbach alpha $(\alpha)$ index is 0.80 , that indicate a good reliability.

\section{Data Analysis and Findings}

Table 1 shows demographic data. As it is shown, most of the respondents were male and married with 31 to 40 years of age. Their level of education falls mostly on categories of high school graduate and bachelor degree.

Table 2 represents descriptive statistics of variables. As it can be seen, all variables have a mean value of greater than 3 which among them the changed behavior has the largest mean of 3.3948 while interest for action has the lowest mean of 3.1331. Standard deviations range from 0.58894 to 0.76572 and interest for action has the largest standard deviation of 0.04892 .

Table 3 shows the results of hypotheses testing. The results reveal that $\tau$-value of all variables are positive and their mean values are greater than 3 . Also, their significance (2-tailed) is less than 0.05 , that is, the means of all variables have a significant difference with 3 . The last two columns (lower and upper) show significance of each variable at $95 \%$ confidence level. Thus, based on the results all hypotheses are supported.

Table 4 represents the Pearson correlation of attention toward action, interest for action, desire for action and behavioral change and their significance. As it is shown, the correlation of all variables are significant at $95 \%$ confidence level ( $\mathrm{Sig}<0.05)$. The correlation coefficient of attention toward action and interest for action is positive and equal to 0.46 , so these two variables have positive and significant linear relations with each other. Also, the correlation coefficient of desire for action with attention toward action and interest for action are positive and respectively 0.337 and 0.604 , it means that there is a positive linear relation between desire for action and attention toward action, even though it's not so strong. Also, the linear relation of desire for action with interest for action is positive and strong. Finally the correlation coefficients of behavioral change with attention for action and interest for action and desire for action are positive and respectively $0.345,0.438$ and 0.573 . It shows that the relations between behavioral change with attention toward action and interest for action are positive and significant. 
Table 5 shows the multiple regression analysis of attention toward action, interest for action and desire for action with behavioral change. Multiple R is 0.598 , which shows the correlation of independent with dependent variables after considering all internal correlation of three variables. $\mathrm{R}$ Squares is 0.358 . It means that 35 percent of behavioral change variance can be explained by collection of independent variables. Adjusted R square is 0.350 ; F-value is 44.803 and sig $<0.05$. So, the regression model can explain the changes of dependent variable. Based on Beta coefficient column, desire for action has the greatest effect (0.471) on behavioral change, which shows behavioral change increases by 47 percent due to desire for action. The second most influential factor on behavioral change was attention toward action with Beta coefficient of 0.147, which shows behavioral change increases by 14 percent due to attention toward action. Finally interest for action has the least effects $(0.086)$ on behavioral change, which shows behavioral change increases by 14 percent due to interest for action. Since the significant level of these two variables (i.e., attention toward action and desire for action) are less than 0.05 , it can be concluded that their influence on behavioral change is supported.

\section{Conclusion}

The results provide valuable insights into understanding the nature and impact of TV advertisement in four stages of attention, interest, desire and finally changes made in conservation behavior of audience. In fact, TV have some main privileges such as access to large audience in a cost-efficient manner, sound and moving images, high attractiveness, attracting attention that made it as a good and effective media among others. Based on $\tau$-test analysis all hypotheses of the study were supported. It means that TV advertisement of electric conservation in Isfahan channel was effective in attracting attention of audience, creating interest and desire for action, and finally lead to a behavioral change. There for, based on these results, we can say that TV advertisement was effective in general. Also, for more and supplementary analysis we used Pearson correlation to understand that whether there is a correlation between these four variables. The Pearson correlation showed that each variable have positive and significant relations with other, which by increase or decrease in one variable, another variable will increase or decrease. Furthermore, for understanding which variable can predict better the behavioral change, we used regression analysis. The regression analysis revealed that desire for action is the best predicting factor for behavioral changes between attention and interest for action. In fact, by increasing the first and third stage of the model, the probability of behavioral changes becomes more. What can be concluded from the results is that the taking attention of audience is the first task that all advertisers should consider it in their advertising. Secondary, they should try to prepare context and requirements of creating desire for action, as much as they can. But, there is an important point that we should consider, and it is the fact that only 35 percent of behavioral changes is explained by these three independent variables and the influencing factors which explain the rest of 65 percent of behavioral change variance is not yet determined. In fact, there are some other variables which justify the changes made in conservation behavior of audience. Thus, it is recommended that future researches take in to consideration the probable influence of other variables.

\section{References}

Andreasen, AR. (2006). Social Marketing in the 21st Century, Thousand Oaks, CA: Sage Publications.

Barry, Thomas E. and Daniel J. Howard. (1990). A Review and Critique of the Hierarchy of Effects in Advertising, International Journal of Advertising, 9 (2), 121-135.

Darby, M. R. and Karni, E. (1973). Free Competition and the Optimal Amount of Fraud, Journal of Law and Economics, 16(1), 67-88, doi:10.1086/466756, http://dx.doi.org/10.1086/466756

Krugman, H. E. (1969). The Impact of Television Advertising: Learning without Involvement, Public Opinion Quarterly, 29: 349-56, doi:10.1086/267335, http://dx.doi.org/10.1086/267335

Lavidge, R. C., and G. A. Steiner. (1961). A Model for Predictive Measurements of Advertising Effectiveness, Journal of Marketing, 25: 59-62, doi:10.2307/1248516, http://dx.doi.org/10.2307/1248516

Mackey. A. (2005 ). The Practice of Advertising, Elsevier Butterworth, Fifth Edition, Sydney, Australia.

Macarthy,E,Joseph and McDaniel,Carl.(2000). Basic Marketing, Richard,D,Irwin,Inc,University Book Stall.

Mohammadian, Mahmood. (2006). Advertisement Management, Horoufiyeh Publishing, Second Edition.

Moore, S.E. (2004). Children and Changing World of Advertisements, Journal of Business Ethics, Vol. 52, pp. 161-7, doi:10.1023/B:BUSI.0000035907.66617.f5, http://dx.doi.org/10.1023/B:BUSI.0000035907.66617.f5

Nelson, P. (1974). Advertising as Information, The Journal of Political Economy, 82(4), 729-754, doi:10.1086/260231, http://dx.doi.org/10.1086/260231 
Patsioura. F. Vlachopoulou. M. and Manthou. V. (2009). A New Advertising Effectiveness Model for Corporate Advertising Websit, A Relationship Marketing Approach, International Journal of Bench Marking, Vol. 16, No. 3, pp. $372-386$.

Peattie,K,and Peattie,S. (2009). Social Marketing:A Pathway to Consumption Reduction? Journal of Business Research,No. 62, pp. 260-268, doi:10.1016/j.jbusres.2008.01.033, http://dx.doi.org/10.1016/j.jbusres.2008.01.03

Pedrick, J. H., and Zufryden, F. S. (1991). Evaluating the Impact of Advertising Media Plans: A Model of Consumer Purchase Dynamics Using Single source Data, Marketing Science, 10(2), 111-131, doi:10.1287/mksc.10.2.111, $\mathrm{http}: / / \mathrm{dx}$.doi.org/10.1287/mksc. 10.2.111

Preston, Ivan L. and Thorson, Esther. (1984). The Expanded Association Model: Keeping the Hierarchy Concept Alive, Journal of Advertising Research, 24, 59-65.

Priya, P., Baisya, R.K., and Sharma, S. (2009). Television Advertisements and Children's Buying Behavior, Marketing Intelligence \& Planning,Vol. 28, No. 2, pp. 151-16, doi:10.1108/02634501011029664, http://dx.doi.org/10.1108/02634501011029664

Ramalingam,V.,Palaniappan,B.,Panchnatham,N.,and Palanivel, S. (2006). Measuring Advertising Effectiveness - A Neural Network Approach, Journal of Bussiness Research, No.31, PP. 159-16.

Rao, R. C. (1986). Estimating Continuous Time Advertising Sales Models, Marketing Science, 5(2), 125-142, doi:10.1287/mksc.5.2.125.

Ray, Michael L., Alan G. Sawyer, Michael L. Rothschild, Roger M. Heeler, Edward C. Strong, and Jerome B. Reed. (1973). Marketing Communication and the Hierarchy of Effects, In New Models for Mass Communication Research, Peter Clarke, ed., Beverly Hills, CA: Sage Publishing, 147-176.

Vakratsas, D., \& Tim, A. (1999). How advertising works: What do we really know? Journal of Marketing, 63(1), 26-43, doi:10.2307/1251999.

Zajonc RB. (1984). On the primacy of affect, Am Psychological, 39(2): 117-23 February, doi:10.1037/0003-066X.39.2.117, http://dx.doi.org/10.1037/0003-066X.39.2.117

Zufryden, F. S. (1987). A Model for Relating Advertising Media Exposures to Purchase Incidence Behavior Patterns, Management Science, 33(10), 1253-1266, doi:10.1287/mnsc.33.10.1253, http://dx.doi.org/10.1287/mnsc.33.10.1253

Table 1. Descriptive Statistics Results

\begin{tabular}{|l|l|c|c|}
\hline Characteristics Description & Frequency & Percent \\
\hline \multirow{4}{*}{ Gender } & Female & 89 & 36.3 \\
\cline { 2 - 4 } & Male & 156 & 63.7 \\
\hline \multirow{4}{*}{ Age } & Single & 86 & 35.1 \\
\cline { 2 - 4 } & Married & 159 & 64.9 \\
\hline \multirow{5}{*}{ Education status } & 21 to 30 years & 76 & 31 \\
\cline { 2 - 4 } & 31 to 40 years & 90 & 36.7 \\
\cline { 2 - 4 } & 41 to 50 years & 51 & 20.8 \\
\cline { 2 - 4 } & more than 51 years & 28 & 11.5 \\
\hline \multirow{5}{*}{ Income } & Below high school & 19 & 7.8 \\
\cline { 2 - 4 } & High school & 100 & 40.8 \\
\cline { 2 - 4 } & Bachelor & 92 & 37.6 \\
\cline { 2 - 4 } & Master & 28 & 11.4 \\
\cline { 2 - 4 } & Ph.D & 6 & 2.4 \\
\hline & Below 400 dollars & 55 & 22.4 \\
\cline { 2 - 4 } & 401 to 600 dollars & 87 & 35.5 \\
\cline { 2 - 4 } & 601 to 800 dollars & 60 & 24.5 \\
\cline { 2 - 4 } & 801 to 1000 dollars & 21 & 8.6 \\
\cline { 2 - 4 } & More than 1000 dollars & 22 & 9 \\
\hline
\end{tabular}


Table 2. Descriptive Statistics of Four Dimensions of Advertisement Effectiveness

\begin{tabular}{|l|c|c|c|c|}
\hline \multicolumn{5}{|c|}{ One-Sample Statistics } \\
\hline & $\mathrm{N}$ & Mean & Std. Deviation & Std. Error Mean \\
\hline Attention toward action & 245 & 3.3739 & 0.58894 & 0.03763 \\
\hline Interest for action & 245 & 3.1331 & 0.76572 & 0.04892 \\
\hline Desire for action & 245 & 3.1878 & 0.75635 & 0.04832 \\
\hline Behavioral change & 245 & 3.3948 & 0.73131 & 0.04672 \\
\hline
\end{tabular}

Table 3. Perceptive Statistics of Four Dimensions of Advertisement Effectiveness

\begin{tabular}{|l|c|c|c|c|c|c|c|}
\hline \multicolumn{7}{|c|}{ One-Sample Test } \\
\hline \multicolumn{7}{|c|}{ Test Value =3 } \\
\hline & t & df & Sig. (2-tailed) & Mean Difference & Lower & Upper & Test Result \\
\hline & 9.937 & 244 & 0.000 & 0.37388 & .2998 & 0.4480 & Supported \\
\hline Attention toward action & 3.720 & 244 & 0.007 & 0.13306 & 0.0367 & 0.2294 & Supported \\
\hline Interest for action & 3.886 & 244 & 0.000 & 0.18776 & 0.0926 & 0.2829 & Supported \\
\hline Desire for action & 8.449 & 244 & 0.000 & 0.39475 & 0.3027 & 0.4868 & Supported \\
\hline Behavioral change &
\end{tabular}

Table 4. Pearson Correlation of Four Dimensions of Advertisement Effectiveness

\begin{tabular}{|c|c|c|c|c|c|}
\hline \multicolumn{6}{|c|}{ Correlations } \\
\hline & & Attention toward action & Interest for action & Desire for action & Behavioral change \\
\hline \multirow[t]{3}{*}{ Attention toward action } & Pearson Correlation & 1 & & & \\
\hline & Sig. (2-tailed) & & & & \\
\hline & $\mathrm{N}$ & 245 & & & \\
\hline \multirow[t]{3}{*}{ Interest for action } & Pearson Correlation & $0.460 * *$ & 1 & & \\
\hline & Sig. (2-tailed) & 0.000 & & & \\
\hline & $\mathrm{N}$ & 245 & 245 & & \\
\hline \multirow[t]{3}{*}{ Desire for action } & Pearson Correlation & $0.337 * *$ & $0.604 * *$ & 1 & \\
\hline & Sig. (2-tailed) & 0.000 & 0.000 & & \\
\hline & $\mathrm{N}$ & 245 & 245 & 245 & \\
\hline \multirow[t]{3}{*}{ Behavioral change } & Pearson Correlation & $0.345^{* *}$ & $0.438 * *$ & $0.573 * *$ & 1 \\
\hline & Sig. (2-tailed) & 0.000 & 0.000 & 0.000 & \\
\hline & $\mathrm{N}$ & 245 & 245 & 245 & 245 \\
\hline
\end{tabular}

Table 5. Multiple Regression Analysis of Attention toward action, Interest for action and Desire for action with Behavioral change

\begin{tabular}{|c|c|c|c|c|c|c|}
\hline \multicolumn{7}{|c|}{ Multiple Regression } \\
\hline Multiple R & 0.598 & & & Analysis of & iance & \\
\hline R Square & 0.358 & & df & Sum of Squares & Mean Squares & \multirow{3}{*}{$\begin{array}{l}F=44.803 \\
\text { Sig }=0.000\end{array}$} \\
\hline Adjusted R Square & 0.350 & Regression & 3 & 46.721 & 15.574 & \\
\hline Standard Error & 0.589 & Residual & 241 & 83.774 & 0.348 & \\
\hline \multicolumn{7}{|c|}{ Variables in the Equation } \\
\hline \multicolumn{2}{|l|}{ Variables } & B & $\begin{array}{c}\text { Std. } \\
\text { Error }\end{array}$ & Beta & $\tau$ & Sig \\
\hline \multicolumn{2}{|c|}{ Attention toward action } & 0.182 & 0.072 & 0.147 & 2.518 & 0.012 \\
\hline \multicolumn{2}{|l|}{ Interest for action } & 0.082 & 0.066 & 0.086 & 1.246 & 0.214 \\
\hline \multicolumn{2}{|l|}{ Desire for action } & 0456 & 0.063 & 0.471 & 7.249 & 0.000 \\
\hline \multicolumn{2}{|l|}{ Constant } & 1.07 & 0.238 & & 4.492 & 0.000 \\
\hline
\end{tabular}

